\title{
Changes and Differentials in the Prevalence of Activity Limitations among Finns Aged 65-74: Comparison of the Mini-Finland Health Examination Survey (1978-80) and the FINRISK-97 Senior Survey (1997)
}

\author{
TUIJA MARTELIN, Ph.D., Senior Researcher ${ }^{1}$ \\ SEPPO KOSKINEN, MD, Ph.D., Chief Physician ${ }^{1}$ \\ ANNA KATTAINEN, MD, Researcher ${ }^{1}$ \\ PÄIVI SAINIO, M.Sc., Researcher ${ }^{1,2}$ \\ ANTTI REUNANEN, MD, Ph.D., Head of Laboratory ${ }^{1}$ \\ ARPO AROMAA, MD, Ph.D., Research Professor ${ }^{1}$ \\ ${ }^{1}$ National Public Health Institute (KTL), Department of Health and Functional \\ Capacity, Helsinki, Finland \\ ${ }^{2}$ ORTON, Orthopaedic Hospital, Rehabilitation Unit, Invalid Foundation, \\ Helsinki, Finland
}

\begin{abstract}
This study analyses time trends in the prevalence of activity limitations and consequent need for help according to gender, education and marital status among Finns aged 65-74 years. The study is based on the Mini-Finland Health Examination Study carried out in 1978-80 and the FINRISK-97 Senior Survey collected in 1997.

During the past 20 years, functional capacity of the elderly at ages 65 to 74 has improved markedly. Women, more often than men, have limitations in several activities, but the reverse is true in some activities. Persons with higher than basic education have less activity limitations than others. Married or cohabiting men report fewer difficulties in several activities than other men, but among women differences according to marital status are small. A continuation of the observed decline in functional limitations would significantly attenuate the increasing trend in the burden of disability that is to be expected because of the ageing of the population
\end{abstract}

Keywords: Functional capacity, elderly, Finland 


\section{Introduction}

In 1980, there were about 577,000 men and women in Finland aged 65 years or over, covering 12 per cent of the total population. Twenty years later, the corresponding figures were 777,000 and 15 per cent, and it is predicted that by the year 2015 the total number of people in this age group will exceed one million, which constitutes more than 20 per cent of the total predicted population (Central Statistical Office of Finland 1982; Statistics Finland 2001). Consequently, the health status and functional capacity of the elderly population will be a crucial factor with regard to the need for care and help in the future. In order to be adequately prepared for the expected increase in the demand for services in the health-care and social sectors, we need information on recent changes in functional capacity among the aged. Moreover, information about the factors that help maintain functional capacity at older ages would benefit efforts to increase the well-being of the elderly and to decrease the economic and social burden implied by the ageing of the population.

The finding concerning the decline in mortality from degenerative diseases and the consequent increase in life expectancy at older ages in the 1970s and the 1980s - a phenomenon that is sometimes called the fourth stage of the epidemiological transition (Olshansky and Ault 1986) - aroused both pessimistic (e.g. Gruenberg 1977) and optimistic (e.g. Fries and Crapo 1981) visions of the health status and functional capacity of the growing population of the elderly. Since then, a lot of research efforts have been devoted to finding out which one of these two contrasting scenarios seems more realistic, or what could be done to prevent the pessimistic outlook from coming true.

Evidence accumulated so far in several countries seems to support the optimistic view over the pessimistic one. For example, in the National Long Term Care Surveys (NLTCS) carried out in the U.S. in 1982, 1989, and 1994, an evident decline was observed in chronic disability at ages 65 or over (Manton et al. 1997). A declining trend in the prevalence of disability among those aged 65 or over was observed also in the Medicare Current Beneficiary Survey among the American elderly from 1992 to 1996 (Waidmann et al. 2000). While the National Health Interview Survey (NHIS) pointed to increasing disability prevalence during the 1970s (e.g. Verbrugge 1984), later trends based on the same data source suggested a decline in disability (e.g. Crimmins et al. 1997). On the other hand, the findings of the Longitudinal Study on Aging (LSOA) showed increases in the prevalence of disability at some times after 1984, and it has been claimed that secular changes found in both the NHIS and the LSOA data are fluctuations rather than consistent trends (Crimmins et al. 1997). The British General Household Study (GHS) and other British surveys suggest a decrease from 1976 to 1994 in serious disability, but no consistent decline in milder health impairments (Grundy 1997). Some 
improvement in several daily activities has been reported in Denmark between 1987 and 1994 (Kjøller et al. 1995), and a decline in mobility restrictions in Sweden since 1968 (Ahacic et al. 2000; Folkhälsorapport 1997).

The findings from Finnish studies also mainly point to a decline in disability at older ages (e.g. Jylhä et al. 1992; Pohjolainen et al. 1997; Laukkanen et al. 1999; Sulander et al. 2000; Pitkälä et al. 2001), while contrasting changes have been reported as well (Anttila 1991; Jylhä et al. 1992; Winblad et al. 2001).

It is well known that health is not evenly distributed within populations. While women enjoy a longer life expectancy than men in most countries, they tend to report disability at older ages more frequently than men; poor socioeconomic status and low education are usually associated with high prevalence of disability (e.g. Ostir et al. 1999; Stuck et al. 1999; Melzer et al. 2001). Similar patterns are found in Finnish studies as well (e.g Jylhä 1993; Manderbacka 1995; Rahkonen and Takala 1997; Valkonen et al. 1997). Differences according to marital status are found in some studies (e.g. Rahkonen and Takala 1997; Sulander et al. 2000), but not in others (e.g. Grundy and Glaser 2000). There are also different findings with regard to the marital status group with the highest risk of disability. For example, in the Finnish Survey of Living Conditions, in 1994, divorced men proved to have a higher prevalence of disability than other men (Rahkonen and Takala 1997). Meanwhile, in the survey of health behaviour among the Finnish elderly in 1999 (Sulander et al. 2000), the widowed elderly among both sexes reported more problems than the other groups.

Since the 1970s, there has been a decline in the gender difference in mortality in several countries, including Finland (Trovato and Lalu 1996; Aromaa et al. 1999). On the contrary, there are indications of an increase in mortality differences according to socioeconomic position (e.g. Valkonen 1999). In addition, the mortality gap between marital status groups, favouring the married, has markedly grown at least in Finland (Koskinen, Martelin and Rissanen 1999). Less is known about possible trends in sociodemographic differentials in functional capacity, or to put it in other words, differential trends in disability among subgroups of the elderly population. Information about them would, however, benefit efforts to reduce inequities in health in general. It would contribute to the search for factors that help maintain functional abilities up to older ages as well as to outline the potential for further improvements in functional capacity at older ages in the future.

In this study, we compare the findings concerning activity limitations and need for help from two samples compiled almost 20 years apart, representing men and women aged 65-74 years living in the southern or eastern parts of Finland. These data sets are based on comparable study protocols, and they provide identical questions of functional abilities and comprehensive data on health status. The 
participation rate is high in both studies. On the basis of these data, we aim to find out

(1) How the prevalence of activity limitations and consequent need for help have changed in Finland among those aged 65-74 years;

(2) What kind of differentials are found in the prevalence of activity limitations and need for help according to gender, education and marital status, and whether there has been any change in these differentials during the past 20 years;

(3) The extent to which the changes in the need for help can be explained by changes in the sociodemographic structure of the population and by trends in the prevalence of different diseases or certain risk factors indicating life style.

\section{Material and methods}

The material of the study consists of two data sets, the first consisting of a part of the Mini-Finland Health Examination Study carried out in 1978-80, and the second comprising the data from the FINRISK-97 Senior Survey collected in 1997. Data collected in health interviews and by means of self-administered questionnaires in both studies were used to determine one's self-reported activity limitations, diseases and disorders, risk factors, and sociodemographic characteristics.

\section{The data sets}

The study population of the Mini-Finland Health Examination Study consisted of a stratified two-stage cluster sample representing the whole country. The total sample included 8,000 individuals aged 30 years or over, 95 per cent of whom participated in the health interview and 86 per cent in the first phase of the health examination. In order to reach comparability with the other data set, we will consider only the sub-sample of those 65-74-year-old subjects who lived in the southern or eastern parts of Finland (the southern and eastern social insurance areas) and who participated in the health examination. Altogether, 216 men and 320 women in the Mini-Finland data fulfilled these criteria and were included. The Mini-Finland Health Examination Survey consisted of several phases (for a more comprehensive description, see Aromaa et al. 1989). In this study, data collected in the health interview by trained nurses as well as in a self-administered questionnaire are used.

The second data set comes from the FINRISK-97 Senior Survey, which belongs to a series of cross-sectional population surveys carried out every fifth year in Finland since 1972 (e.g. Vartiainen et al. 2000). The FINRISK-97 Senior Survey was conducted in two areas, namely, in North Karelia, which is located in eastern Finland, and in Helsinki (the capital city) and its neighbouring city Vantaa, both of 
which are located in southern Finland. The areas included in the FINRISK-97 Senior Survey covered 30 per cent of the population aged 65-74 years living in the eastern and southern social insurance areas, which are the areas included in the MiniFinland subset of our data.

The FINRISK-97 Senior Survey protocol included a self-administered questionnaire mailed together with the invitation, and a field examination including e.g. a health interview by trained nurses and a clinical examination. Home visits were carried out by nurses in case of non-participation. The original sample of the study included 500 men and 250 women aged 65 to 74 years in both areas, totalling 1,500. Altogether, 86 per cent of the sample ( 858 men and 430 women) participated in the health interview and 74 per cent in the field examination. In this study, we include all subjects who participated in the health interview.

\section{Indicators of activity limitations and need for help}

Both studies included an identical series of questions eliciting information on whether the person could perform certain activities without difficulty, with some difficulty, with marked difficulty, or not at all. Basic activities of daily life included moving about in the house, getting in and out of bed, and dressing and undressing. Usual activities of daily life were indicated by carrying a shopping bag of $5 \mathrm{~kg}$ for $100 \mathrm{~m}$, walking $400 \mathrm{~m}$, climbing a flight of stairs, and managing grocery shopping. Occasional activities of daily life included clipping one's toenails, reading a newspaper, performing heavy housework such as cleaning, and travelling on public transportation. In this study activity limitation was defined as at least marked difficulty in performing the activity.

Two summary measures were constructed to indicate need for help due to activity limitations (see Aromaa et al. 1989, Mäkelä et al. 1993). Those who reported having at least marked difficulty with any of the activities listed above (basic, usual, or occasional activities) or being nearly or completely blind were considered in need of help at least occasionally; those who had at least marked difficulty with any of the basic or usual activities or were nearly or completely blind were considered in need of regular help, either daily or at least several times a week. 'Daily or frequent need for help' is thus a subset of 'at least occasional need for help'.

\section{Sociodemographic factors}

In this study, we consider differences in activity limitations by gender, marital status, and educational level. Moreover, age and region of residence (southern vs. eastern Finland) are controlled for in the analyses. The proportion of elderly living in eastern Finland was smaller in the Mini-Finland sample than in the latter survey. 
Marital status was classified similarly in both studies (married, cohabiting, single, divorced or separated, and widowed). In this study we collapsed the categories into married or cohabiting, and others. Differences in the marital structure were rather small between the two surveys; the proportion of married or cohabiting women was slightly larger in the 1997 survey than in the 1978-80 survey. Educational level was classified into basic education or less, and higher than basic education. The proportion of those with higher than basic education was about twice as large among both sexes in the 1997 survey compared with the earlier one.

\section{Diseases, obesity, and smoking}

In order to obtain information from as many subjects as possible, we use the data collected by self-administered questionnaires and in the health interview to obtain the prevalence of selected diseases and disorders. In the Mini-Finland Survey, the respondents were asked whether a physician had ever diagnosed any of the diseases listed in the questionnaire. In the FINRISK-97 Senior Study, the wording of the question was "Have you, during the past 12 months, had any of the following diseases diagnosed or treated by a physician?" In the case of myocardial infarction, stroke, cerebral haemorrhage or thrombosis, and diabetes, the respondent was asked whether these diseases had ever been diagnosed by a physician. The list of diseases applied in this study is given in a footnote of Table 5.

We consider two indicators of health-related behaviour, namely, obesity and smoking. Obesity was defined as BMI $\geq 30$. Smoking status was classified into current regular smokers, former smokers, and never-smokers.

\section{Statistical methods}

Prevalence of limitations in separate activities and need for help according to the two summary indicators was first calculated from the 1978-80 data and the 1997 data by sex and five-year age group (65-69, 70-74 years). Differences between the two data sets were tested by means of ordinary chi-square test (when applicable) or with Fisher's exact test. Differences according to gender, education, marital status, and study period (1978-80 and 1997) in limitations of separate activities and in the two summary indicators of need for help were then examined by means of logistic regression, controlling for age (continuous explanatory variable) and region (southern vs. eastern Finland). Analyses for education and marital status were performed separately for women and men. The differences according to education and marital status are illustrated by means of sex-specific proportions of those showing at least occasional need for help, standardised for age (five-year age group) and region by the direct method. 
Finally, the impact of diseases, obesity and smoking, educational structure and marital structure on the difference between the samples in the need for help was examined by means of logistic regression, controlling for age and region. Differences between the two surveys are presented by means of odds ratios (1997/ 1978-80) according to different models, including age, region, and either one explanatory factor or several factors simultaneously. The analyses are performed separately for the two indicators of need for help as well as for men and women. The GENMOD procedure of SAS 6.12 was applied in the modelling.

\section{Results}

A marked difference between the 1978-80 sample and the 1997 sample is observed, the prevalence of limitations in almost every activity being smaller in the latter study among both sexes and in both age groups (Table 1). The improvements were more marked among those aged 65 to 69 years than in the older age group. In the younger age group, the proportion of elderly among both sexes who were considered in need of help frequently or occasionally more than halved. In the older age group, a significant decline in the prevalence was found only in the case of the milder indicator (at least occasional need for help), while the decrease in daily or frequent need for help was more modest.

The gender difference in the prevalence of activity limitations varied according to the activity in question (Table 2). Men, more often than women, had limitations in dressing and undressing, and slightly more often showed difficulties in moving inside their dwelling, the latter difference being visible only in the 1978-80 data. Women were more likely than men to suffer from difficulties in carrying $5 \mathrm{~kg}$ for $100 \mathrm{~m}$, using public transportation, and doing heavy housework, the latter difference being more marked in the 1997 study than in the data from 1978-80. Consequently, according to both summary indicators, women were more likely than men to show need for help due to activity limitations. The gender difference in at least occasional need for help was more marked in 1997 than during the earlier period, which is mostly due to the greater improvement among men in the ability to do heavy housework. Looking at this interaction from the other angle, the decrease in difficulties in doing heavy housework and, consequently, in the need for at least occasional help, was more marked among men than among women. 


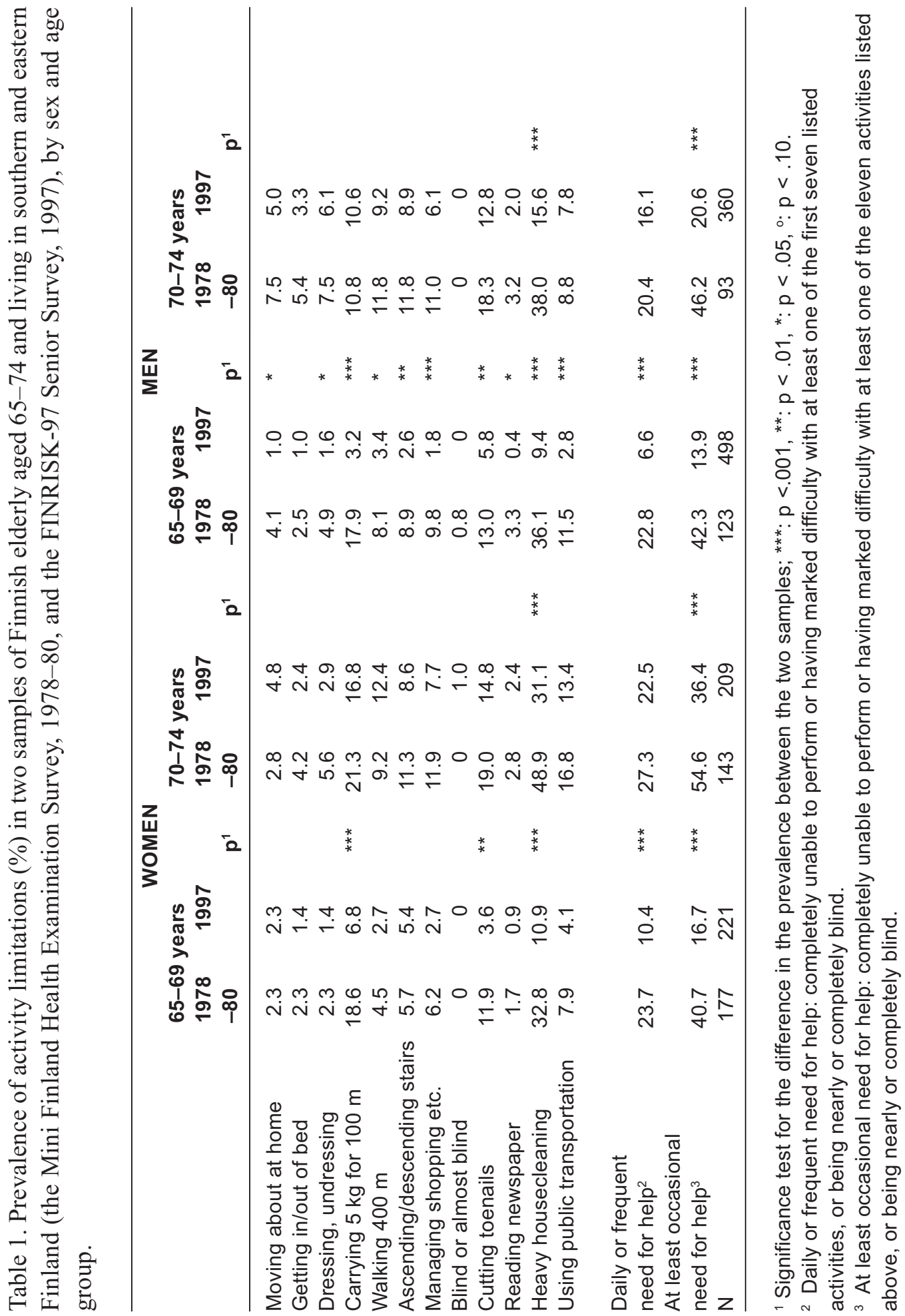


Table 2. Gender differences in the prevalence of activity limitations and changes in them from 1978-80 to 1997 among Finnish elderly aged 65-74 and living in southern and eastern Finland.

\begin{tabular}{|c|c|c|c|c|}
\hline & $\begin{array}{l}\text { Gender diffe } \\
\text { men/women }\end{array}$ & $\begin{array}{l}\text { ence: } \\
\text { (OR })^{1,3}\end{array}$ & $\begin{array}{l}\text { Secular cha } \\
1997 / 1978\end{array}$ & $\begin{array}{l}e: \\
(O R)^{2,3}\end{array}$ \\
\hline Moving about at home ${ }^{4}$ & 1.24 & & 0.68 & \\
\hline & 1978-80: & $2.40^{\circ}$ & Men: & $0.43^{*}$ \\
\hline & 1997: & 0.85 & Women: & 1.22 \\
\hline Getting in/out of bed & 1.19 & & $0.50^{*}$ & \\
\hline Dressing, undressing & $1.85^{\star}$ & & $0.45^{\star *}$ & \\
\hline Carrying $5 \mathrm{~kg}$ for $100 \mathrm{~m}$ & $0.61^{* *}$ & & $0.43^{* * *}$ & \\
\hline Walking $400 \mathrm{~m}$ & 1.08 & & 0.72 & \\
\hline $\begin{array}{l}\text { Ascending/ } \\
\text { descending stairs }\end{array}$ & 0.98 & & $0.57^{* *}$ & \\
\hline Managing shopping etc. & 0.96 & & $0.38^{* * *}$ & \\
\hline Cutting toenails & 1.05 & & $0.46^{* * *}$ & \\
\hline Reading newspaper & 1.04 & & $0.41^{*}$ & \\
\hline Heavy housecleaning ${ }^{4}$ & $0.67^{* *}$ & & $0.27^{* * *}$ & \\
\hline & 1978-80: & 0.88 & Men: & $0.21^{* * *}$ \\
\hline & 1997: & $0.55^{\star * *}$ & Women: & $0.33^{* * *}$ \\
\hline Using public transportation & $0.70^{\circ}$ & & $0.49^{* *}$ & \\
\hline $\begin{array}{l}\text { Daily or frequent } \\
\text { need for help }\end{array}$ & $0.71^{* *}$ & & $0.45^{\star * *}$ & \\
\hline At least occasional & $0.69^{* *}$ & & $0.28^{* * *}$ & \\
\hline need for help ${ }^{4}$ & 1978-80: & 0.89 & Men: & $0.23^{* * *}$ \\
\hline & 1997: & $0.59^{* * *}$ & Women: & $0.35^{\star * *}$ \\
\hline
\end{tabular}

1 Odds ratios describing gender differences are based on model age+region+sex+study; when the interaction between sex and study is at least suggestive $(p<.10)$, the odds ratio for the gender difference is also given separately for the two study periods.

${ }^{2}$ Odds ratios describing secular change are based on model age+region+sex+study; when the interaction between sex and study is at least suggestive $(p<10)$, the odds ratio for the difference between the two study periods is also given separately for men and women.

${ }^{3}$ Supplied with the test of $\mathrm{H}_{0}$ : OR=1; ${ }^{* * *} \mathrm{p}<.001,{ }^{* *} \mathrm{p}<.01,{ }^{*} \mathrm{p}<.05$,

$\circ p<.10$ (otherwise $p \geq .10$ ).

${ }^{4}$ The interaction between sex and study period is significant at $p<.10$. 
Table 3. Differences between education groups in the prevalence of activity limitations (odds ratios: basic education/higher education ${ }^{1}$ ), men and women aged 65-74 and living in southern and eastern Finland in 1978-80 and 1997.

\begin{tabular}{|c|c|c|c|}
\hline Activity & WOMEN & MEN & \\
\hline Moving about at home & 0.71 & 1.94 & \\
\hline Getting in/out of bed & 1.58 & 1.50 & \\
\hline Dressing, undressing & 2.44 & 1.35 & \\
\hline Carrying $5 \mathrm{~kg}$ for $100 \mathrm{~m}$ & 1.55 & $2.04^{*}$ & \\
\hline Walking $400 \mathrm{~m}$ & 1.52 & 1.65 & \\
\hline Ascending/descending stairs & 1.56 & $1.90^{\circ}$ & \\
\hline Managing shopping etc. ${ }^{2}$ & 1.50 & $\begin{array}{l}1.41 \\
\text { 1978-80: } \\
\text { 1997: }\end{array}$ & $\begin{array}{l}6.32^{\circ} \\
0.94\end{array}$ \\
\hline Cutting toenails & $2.93^{* *}$ & $2.19^{* *}$ & \\
\hline Reading newspaper & 5.42 & 2.39 & \\
\hline Heavy housecleaning ${ }^{3}$ & $1.81^{* *}$ & $\begin{array}{l}1.63^{*} \\
\text { 1978-80: } \\
\text { 1997: }\end{array}$ & $\begin{array}{l}2.86^{* *} \\
1.31\end{array}$ \\
\hline $\begin{array}{l}\text { Using public } \\
\text { transportation }\end{array}$ & $1.98^{\circ}$ & $1.79^{\circ}$ & \\
\hline $\begin{array}{l}\text { Daily or frequent } \\
\text { need for help }\end{array}$ & $1.60^{\circ}$ & $1.74^{*}$ & \\
\hline $\begin{array}{l}\text { At least occasional } \\
\text { need for help }\end{array}$ & $1.66^{*}$ & $2.06^{* * *}$ & \\
\hline
\end{tabular}

1 Odds ratios describing educational differences are based on model age+region+education+study; when the interaction between education and study is at least suggestive $(p<.10)$, the odds ratios for the educational difference are also given separately for the two study periods. The statistical test for

$\mathrm{H}_{0}$ : OR=1 is performed; ${ }^{* * *} \mathrm{p}<.001,{ }^{* *} \mathrm{p}<.01,{ }^{*} \mathrm{p}<.05,{ }^{\circ} \mathrm{p}<.10$ (otherwise $\mathrm{p} \geq .10$ ).

2 The interaction between education and study period is significant at $p<.05$ among men.

${ }^{3}$ The interaction between education and study period is significant at $p<.10$ among men. 
Those with more than basic-level education almost invariably showed less activity limitations than the elderly with basic education or less (Table 3). Particularly, cutting toenails, doing heavy housework, and using public transportation caused marked difficulties less often in both sexes among those with more education than among those with lower educational level. Moreover, significant or suggestive differences were found between educational groups among men in carrying a shopping bag for $100 \mathrm{~m}$, ascending/descending stairs and managing shopping, the latter difference being visible only during 1978-80. Altogether, educational differences were more marked in connection with the milder indicator of need for help (at least occasional need for help) than the one summarising the limitations in basic or usual activities of daily life (daily or frequent need for help). Differences according to education were broader among elderly men than women.

No convincing evidence was found about marked changes in educational differences in the need for help between the two study periods. However, among men, the prevalence of marked difficulties in managing shopping declined in the basic education group but not among those with more education, resulting in a disappearance of educational difference in this activity. Likewise, in 1978-80, men with basic education reported more difficulties in doing heavy housework than men with higher education, but in 1997 the difference was very small, reflecting a faster decline in the prevalence of difficulties among men with lower education.

Widowed, single and divorced/separated men were more likely to show marked difficulties in all activities than married or cohabiting men (Table 4). The prevalence of limitations in cutting toenails was clearly lower among married or cohabiting men than among other men in 1997, while no difference was found in the earlier study. There were signs of a similar pattern in connection with heavy housework (results not shown here). As a result, the differences between marital status groups in needing at least occasional help grew wider. In the case of basic or usual activities of daily life, no evidence of differential velocity of improvements was found.

On the contrary, among women, differences between marital status groups were very small. Only marked difficulties in cutting toenails, managing shopping, and using public transportation were more frequent among widowed, single or divorced/ separated women than among married or cohabiting women. No significant interactions between marital status and study period were found among women. 
Table 4. Differences between marital status groups in the prevalence of activity limitations (odds ratios: not married or cohabiting vs. married or cohabiting ${ }^{1}$ ), men and women aged 65-74 and living in southern and eastern Finland in 1978-80 and 1997.

\begin{tabular}{llll}
\hline & WOMEN & MEN & \\
\hline Moving about at home & 0.97 & 1.59 & \\
Getting in/out of bed & 0.74 & $2.32^{*}$ & \\
Dressing, undressing & 0.65 & 1.73 & \\
Carrying 5 kg for 100 m & 1.02 & $1.67^{*}$ & \\
Walking 400 m & 0.94 & 1.37 & \\
Ascending/descending stairs & 1.02 & $1.64^{\circ}$ & \\
Managing shopping etc. & $1.77^{\circ}$ & $2.23^{* *}$ & \\
Cutting toenails & $1.80^{*}$ & $1.90^{* *}$ & \\
& & $1978-80:$ & 0.79 \\
& & $1997:$ & $2.53^{* * *}$ \\
Reading newspaper & 1.44 & 1.65 & \\
Heavy housecleaning & 0.92 & $1.55^{*}$ & \\
Using public transportation & $1.59^{\circ}$ & $1.63^{\circ}$ & \\
Daily or frequent need for help & 1.17 & $1.65^{*}$ & \\
At least occasional need for help ${ }^{3}$ & 0.97 & $1.67^{* *}$ & \\
& & $1978-80:$ & 0.76 \\
& & $1997:$ & $2.20^{* * *}$ \\
\hline
\end{tabular}

${ }^{1}$ Odds ratios describing differences between marital status groups are based on model age+region+marital status+study; when the interaction between marital status and study is at least suggestive $(p<.10)$, the odds ratios for the difference between marital status groups are also given separately for the two study periods. Statistical test for the hypothesis $\mathrm{H}_{0}: \mathrm{OR}=1$ is performed; ${ }^{* *} \mathrm{p}<.001,{ }^{* *} \mathrm{p}<.01,{ }^{*} \mathrm{p}<.05$,

${ }^{\circ} p<.10$ (otherwise $p \geq .10$ ).

2 The interaction between marital status and study period is significant at $p<.05$ among men.

${ }^{3}$ The interaction between marital status and study period is significant at $p<.01$ among men.

Figure 1 illustrates the main findings of differences between men and women, educational groups and marital groups, as well as those between the two studies in the prevalence of at least occasional need for help. The most striking feature in the figure is the decline in the prevalence of need for help in each subgroup. Moreover, it demonstrates the emergence of differences according to marital status among men, the lack of marital status differences among women, and the fact that consistent educational differences are found in both studies and both genders, although they are more marked among men. 
Figure 1. The prevalence of at least occasional need for help according to education and marital status, by sex and study among men and women aged 65 to 74 years in two areas of Finland in 1978-80 and 1997 (standardized for age and region, with $95 \%$ confidence limits).

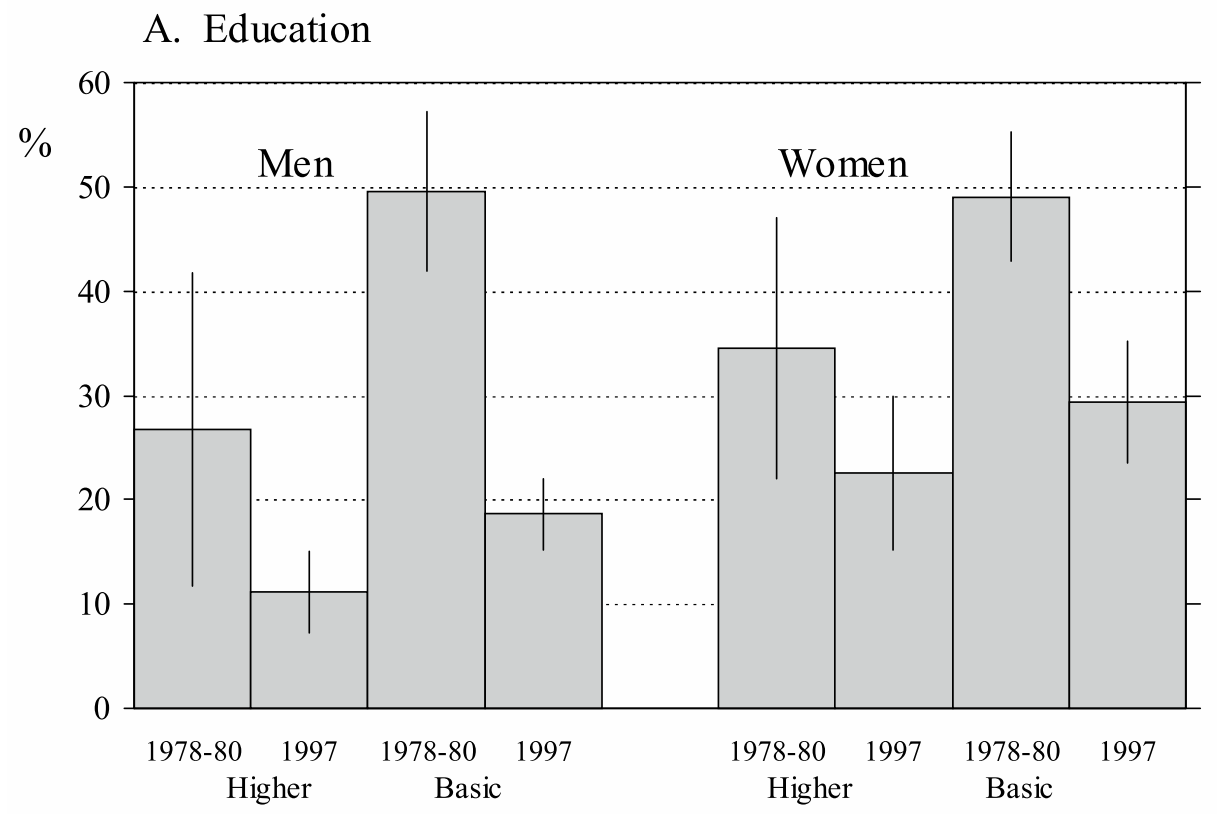

B. Marital status

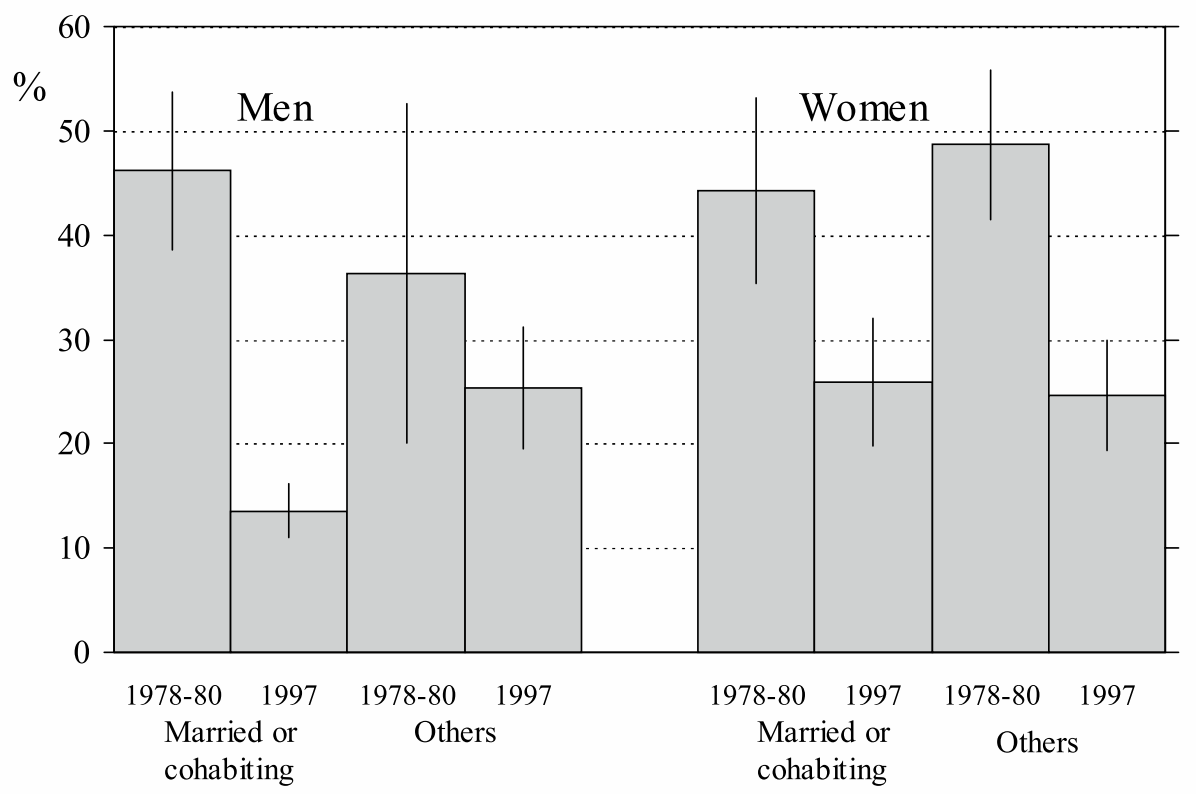


Many diseases affect physical, cognitive and/or social functioning and thereby cause activity limitations and need for help. The prevalence of most diseases included in this study was clearly smaller in the 1997 data than in the 1978-80 data. This is particularly true for cardiovascular diseases, excluding hypertension, in men (see Kattainen et al. 2001). Obesity and smoking also showed a significant association with need for help. Among men and older women the prevalence of obesity was larger in the 1997 study than in the survey carried out in 1978-80. The proportion of current smokers had decreased among men, but increased among women.

However, controlling for the difference in the prevalence of diseases, obesity and smoking and in the educational and marital structure of the two samples had hardly any effect on the OR describing the change in the need for help (Table 5). Changes in the prevalence of cardiovascular diseases and in the educational structure of the population had the largest contributions to the difference in the prevalence of daily or frequent need for help between the two studies. Controlling for both of these variables changed the odds ratio of the 1997 study to that of 1978-80 from 0.54 to 0.60 among women and from 0.38 to 0.46 among men. Their effect on the difference in occasional need for help was even more modest.

\section{Discussion}

A marked difference in the prevalence of self-reported activity limitations was observed between two samples collected in 1978-80 and 1997 representing Finnish elderly aged 65 to 74 years in two geographic areas. The proportion of those reporting at least marked difficulties was clearly smaller in the 1997 sample than in the earlier one in almost all activities included in this study. Consequently, the estimated need for help based on activity limitations was smaller in the more recent sample. The difference between the two samples was particularly large in heavy housecleaning and managing shopping, but almost similar differences were found in the other items, too. Differences were more marked in the age group 65-69 years than in the older five-year age group, especially among women.

Comparison of the findings of this study to those of earlier research is not straightforward because studies differ in several relevant aspects, such as the definitions and indicators of disability or activity limitations, the age range covered, or the degree of representativeness. However, the general picture obtained in this study fits with the findings of the majority of earlier studies carried out in several countries, reporting improvements in functional capacity (e.g. Kjøller et al. 1995; Grundy 1997; Manton et al. 1997; Pohjolainen et al. 1997; Laukkanen et al. 1999; Ahacic et al. 2000; Sulander et al. 2000; Waidmann et al. 2000). 
Table 5. Difference in the need for help between the Mini-Finland Health Examination Survey (1978-80) and the FINRISK Senior Survey (1997): effects of controlling for diseases, obesity, smoking, education and marital status, by indicator of need of help and sex, men and women aged 65-74 living in southern or eastern Finland (odds ratios 1997/1978-80).

\begin{tabular}{|c|c|c|c|c|}
\hline \multirow{3}{*}{ Variables controlled for } & \multicolumn{4}{|c|}{ Odds ratio: $1997 / 1978-80^{1}$} \\
\hline & \multicolumn{2}{|c|}{$\begin{array}{l}\text { Daily or frequent } \\
\text { need for help }\end{array}$} & \multicolumn{2}{|c|}{$\begin{array}{l}\text { At least occasional } \\
\text { need for help }\end{array}$} \\
\hline & Women & Men & Women & Men \\
\hline Age and region & $0.54^{* *}$ & $0.38^{* * *}$ & $0.35^{* * *}$ & $0.23^{* * *}$ \\
\hline \multicolumn{5}{|l|}{ Age, region and $[\ldots]^{2}$} \\
\hline - cardiovascular diseases ${ }^{3}$ & $0.58^{* *}$ & $0.42^{* * *}$ & $0.37^{* * *}$ & $0.24^{* * *}$ \\
\hline - other diseases ${ }^{3}$ & $0.49^{* * *}$ & $0.40^{* * *}$ & $0.33^{* * *}$ & $0.24^{* * *}$ \\
\hline - obesity & $0.52^{* * *}$ & $0.36^{* * *}$ & $0.33^{* * *}$ & $0.22^{* * *}$ \\
\hline - smoking & $0.50^{* * *}$ & $0.39^{* * *}$ & $0.32^{* * *}$ & $0.23^{* * *}$ \\
\hline - education & $0.56^{* *}$ & $0.42^{* * *}$ & $0.38^{* * *}$ & $0.25^{\star * *}$ \\
\hline - marital status & $0.54^{* *}$ & $0.37^{* * *}$ & $0.35^{* * *}$ & $0.22^{* * *}$ \\
\hline \multirow{2}{*}{$\begin{array}{l}\text { - all variables listed above } \\
\text { - cardiovascular diseases } \\
\text { and education }\end{array}$} & $0.49^{* *}$ & $0.45^{\star * *}$ & $0.31^{* * *}$ & $0.24^{* * *}$ \\
\hline & $0.60^{*}$ & $0.46^{* * *}$ & $0.40^{* * *}$ & $0.27^{\star * *}$ \\
\hline
\end{tabular}

${ }^{1}$ Supplied with the test of $\mathrm{H}_{0}: \mathrm{OR}=1 ;{ }^{* * *} \mathrm{p}<.001,{ }^{* *} \mathrm{p}<.01,{ }^{*} \mathrm{p}<.05$.

2 The subsequent models include only one explanatory factor (or a set of factors) at a time, in addition to age and region.

${ }^{3}$ Cardiovascular diseases include myocardial infarction, angina pectoris, heart failure, cerebrovascular disease, and intermittent claudication); other diseases include diabetes, respiratory diseases (asthma, chronic bronchitis, emphysema), musculoskeletal disease (rheumatoid arthritis, other joint disease, low back disorder or other back disease, osteoarthrosis of knee, hip, hand, or other osteoarthrosis), permanent injury or defect due to accident or violence), and mental disorder (mild or severe).

Also the findings concerning gender and educational differences support those obtained in earlier studies (e.g. Jylhä et al. 1993; Manderbacka 1995; Rahkonen and Takala 1997; Ostir et al. 1999; Stuck et al. 1999; Melzer et al. 2001). In most activities, women were more likely to report difficulties than men, and those with a low educational level were more likely to experience activity limitations than those with higher than basic education. The difference in need for help between sexes was larger in the latter sample, while there were some signs of narrowing educational differences in certain activities. This was not, however, reflected in the summary indicators of need for help. These findings are in contrast with those found in mortality that rather suggest a decline in gender differences but a widening in socioeconomic differences (Trovato and Lalu 1996; Aromaa et al. 1999; Valkonen 
1999). On the other hand, in a Swedish study on mobility limitations, no change in occupational differences was found during the period 1968-1991, but gender differences had narrowed (Ahacic et al. 2000). So far, health-monitoring projects have more or less neglected to monitor time trends in sociodemographic differences in functional capacity. Our findings suggest that this aspect ought to be included in the surveillance of health differences and inequities.

In earlier studies, findings concerning differences between marital status groups have not been quite consistent. In this study, married or cohabiting men reported fewer difficulties in several activities than other men, but among women differences between marital status groups were small. Among men, the gap between marital status groups in at least occasional need for help was larger in the 1997 sample than in the 1978-80 study. This was mainly due to a more favourable trend in the ability to cut toenails and do heavy housecleaning among married and cohabiting elderly men than among others. The finding that differences according to marital status had widened is in line with recent trends in mortality differentials in Finland (Koskinen et al. 1999).

There may be several explanations for the marked difference in activity limitations between the 1978-80 data and that collected in 1997. First, we have to consider to what extent these differences could result from artefacts. In both studies, the information on activity limitations was elicited through similar questions asked by a trained nurse in a health interview. Consequently, no bias should have been introduced because of differences in instruments. The study regions in the two studies were not quite identical, but both southern and eastern Finland covered a larger area in the 1978-80 sample than in 1997. There are some indications that the elderly living in the metropolitan area, consisting of the cities of Helsinki, Espoo, Vantaa, and Kauniainen, have better health and functional capacity than those living in other parts of southern Finland (Noro et al. 2000). The decline in disability between the 1978-80 and the 1997 data would be overestimated if "southern Finland" in the latter sample consisted of areas showing better health than those included in the 1978-80 sample. This is not, however, necessarily the case, as southern Finland in the 1997 sample is represented only by Helsinki and Vantaa, while the two other cities of the metropolitan area, advantaged in several respects, are not included.

In general, eastern Finland represents poorer health according to several indicators when compared to the mean level of the country as a whole, while southern Finland approximates the average level or slightly better. The combination of these two areas is thus likely to give a slightly pessimistic picture of the prevalence of activity limitations in the whole country in both periods. Region was included in statistical models in order to adjust for the difference in distribution. 
In addition to the difference in regional distribution, also differences in population structure according to other health-relevant factors might offer at least a partial explanation to the difference in activity limitations between the two samples. Educational level was clearly higher in the 1997 sample than in 1978-80, reflecting the general trend in the Finnish population. Indeed, controlling for education slightly decreased the difference in need for help between the two studies but by no means removed it. Similar findings concerning the role of structural changes have been made in other studies, too (Freedman and Martin 1998, Waidmann and Liu 2000). In our study, the contribution of the change in the educational structure was very modest, although the time interval between the two studies was almost 20 years. Marital status distribution was rather similar in both studies and, consequently, controlling for it did not affect the changes in need for help.

It may also be hypothesised that there has been a change in the role of the elderly so that they as well as their environment expect them to maintain an active attitude towards life and independence in daily activities into a more advanced age than before. This might lead to a tendency towards underestimating the degree of difficulties. Pitkälä et al. (2001) found an increase in an optimistic attitude towards the future among the elderly in a comparison of samples collected in 1989 and 1999. A change in the general atmosphere of this kind could also enhance confidence in one's abilities to carry out daily tasks. On the other hand, it seems unlikely that such changes in expectations and attitudes could have occurred without any improvement in actual performance among the elderly.

We thus conclude that artefacts and structural differences hardly make a major contribution to the observed difference in the prevalence of self-reported activity limitations. Yet it is not evident to what extent the findings can be interpreted to reflect an actual change in the physical and social performance of the elderly. It can be hypothesised that a change in the environment has made it easier to carry out certain activities compared to twenty years ago. For example, typical clothing may have become easier to put on, technical innovations have probably facilitated doing housework and using public transportation, and easier access to a car - either one's own or a taxi - may have contributed to improvement in the ability to manage shopping and other affairs. This interpretation gets support from the fact that among men a difference between educational groups in managing shopping and doing heavy housework was found in 1978-80 but not in 1997. The change may reflect the improvement in material living conditions, which has made it possible to acquire modern conveniences even among the less advantaged groups of the elderly population. 
However, there has been an improvement also in several activities that are probably not very much influenced by changes in the environment or technical innovations, such as carrying a shopping bag or cutting toenails. As several diseases influence one's ability to carry out daily tasks, it could be hypothesised that the decline in the prevalence of various medical conditions contributes to the change in functional capacity. However, in this study only cardiovascular diseases seemed to have a modest contribution to the decline in the prevalence of daily or frequent need for help. The weakness of the explanatory power of the change in morbidity implies that even the elderly suffering from various diseases nowadays have better functional capacity than before. This may reflect an improved management of diseases. On the other hand, it seems likely that the elderly today are in better general health and physical condition than those in older cohorts, owing to different experiences and cumulative exposure to health-damaging or health-promoting conditions during their entire life course (e.g. Kuh and Ben-Shlomo 1997). This would result in maintaining a better functional capacity longer even regardless of possible diseases.

Explanations for the improvement in functional capacity were also sought in the change in smoking habits and the prevalence of obesity. However, these factors had only a modest or even an inverse contribution, as obesity has increased and there is also an increase in smoking among elderly women.

\section{Conclusions}

As a conclusion, it seems likely that the functional capacity of the elderly at ages 65 to 74 has improved markedly during the past 20 years. A continuation of this trend would significantly attenuate the increasing trend in the burden of disability that is to be expected because of the ageing of the population. However, there are also trends that might counteract these positive changes, such as the increase in obesity and smoking among women. Moreover, special attention should be directed to certain risk groups among the elderly, such as non-married men, in which the decline in activity limitations has not been as fast as among other subgroups of the population. Finally, in order to achieve a comprehensive picture of the trends in functional capacity in the elderly, corresponding analyses should be carried out in other elderly age groups as well, using nationally representative data.

\section{Acknowledgements}

We would like to thank the researchers and field workers involved in the planning and implementation of the Mini-Finland Health Survey and the FINRISK-97 Senior Survey. 


\section{References}

Ahacic, K., M.G. Parker and M. Thorslund. 2000. Mobility limitations in the Swedish population from 1968 to 1992: Age, gender and social class differences. Aging (Milan). 12:190-198.

Anttila S. 1991. Functional capacity in two elderly populations aged 75 or over: compartisons at 10 years' interval. Journal of Clinical Epidemiology 44(11):1181-1186.

Aromaa, A., M. Heliövaara, O. Impivaara, P. Knekt, J. Maatela, M. Joukamaa, T. Klaukka, V. Lehtinen, T. Melkas, E. Mälkiä, K. Nyman, I. Paunio, A. Reunanen, K. Sievers, E. Kalimo, V. Kallio. 1989. Health, functional limitations and need for care in Finland. Basic results from the Mini-Finland Health Survey. Helsinki and Turku: Publications of the Social Insurance Institution, Finland, AL:32.

Aromaa, A., S. Koskinen and J. Huttunen. 1999. Health in Finland. Helsinki: National Public Health Institute and Ministry of Social Affairs and Health.

Central Statistical Office of Finland. 1982. Population. Volume 1. Structure of population and vital statistics. Whole country and provinces. Helsinki: Central Statistical Office of Finland.

Crimmins E.M., Y. Saito and S.L.Reynolds. 1997. Further evidence on recent trends in the prevalence and incidence of disability among older Americans from two sources: the LSOA and the NHIS. The journals of gerontology. B, Psychological sciences and social sciences 52B(2):S59-S71.

Folkhälsorapport 1997. Stockholm: Socialstyrelsen, Epidemiologiskt Centrum, Sos rapport 1997:18

Freedman V.A. and L. G. Martin. 1998. Understanding trends in functional limitations among older Americans. American Journal of Public Health 88(10):1457-1462.

Fries J.F. and L.M. Crapo. 1981. Vitality and Aging. Implications of the Rectangular Curve. USA: WH Freeman and Company.

Goldman N., S. Korenman and R. Weinstein. 1995. Marital status and health among the elderly. Social Science \& Medicine 40(12):1717-1730.

Gruenberg E.M. 1977. The failures of success. Milbank Memorial Fund Quarterly 55:324.

Grundy E. 1997. The health and health care of older adults in England and Wales, 18411994. In: The health of adult Britain 1841-1994, edited by J. Charlton and M. Murphy, pp. 182-203. London: Office for National Statistics.

Grundy, E. and K. Glaser. 2000. Socio-demographic differences in the onset and progression of disability in early old age: a longitudinal study. Age and Ageing 29: 149-157.

Jylhä M., J. Jokela, E. Tolvanen, E. Heikkinen, R-L. Heikkinen, S. Koskinen, E. Leskinen, A-L. Lyyra, P. Pohjolainen. 1992. The Tampere Longitudinal Study on Ageing. Description of the study. Basic results on health and functional ability. Scandinavian Journal of Social Medicine, Suppl. 47.

Jylhä M., (editor). 1993. Vanhuusikä muutoksessa - kohorttitutkimus eläkeikäisten tamperelaisten terveydestä ja elämäntilanteesta vuosina 1979 ja 1989. (Old age in transition - a cohort comparison of the health and life situation of the elderly in Tampere in 1979 and 1989; in Finnish, English summary). Sosiaali- ja terveysministeriön selvityksiä 1993:6, Helsinki.

Kattainen A., A. Reunanen, S. Koskinen, T. Martelin, P. Knekt, and A. Aromaa. 2001. Secular changes in prevalence of cardiovascular diseases in elderly Finns. (manuscript, submitted for publication) 
Kjøller, M., N.K. Rasmussen, L. Keiding, H.C.Petersen, and G.A. Nielsen. 1995. Sundhed og sygelighed in Danmark 1994 - og udviklingen siden 1987. Rapport fra DIKEs reprcesentative undersøgelse blandt voksne danskere (in Danish). Copenhagen: Dansk Institute for Klinisk Epidemiologi.

Koskinen, S., T. Martelin, and H. Rissanen. 1999. Mortality differences by marital status a growing public health problem (in Finnish, English summary). Sosiaalilääketieteellinen Aikakauslehti - Journal of Social Medicine 36:271-284.

Kuh D. and Y. Ben-Shlomo, (editors). 1997. A life course approach to chronic disease epidemiology. Oxford: Oxford University Press.

Laukkanen P., R. Leinonen, R. Sakari-Rantala, E. Heikkinen. 1999. Health status and performance in the activities of daily living among 65-69-year-old residents of Jyväskylä in 1988 and 1996 (in Finnish, English summary). In: Cohort differences in the functional capacity, health and leisure activities of 65-69-year-old persons. Observations from the cohort comparisons of the Evergreen project in 1988 and 1996, edited by Heikkinen E., P. Lampinen and T. Suutama, pp. 47-66. (in Finnish, with English summaries). Helsinki: The Social Insurance Institution, Studies in Social Security and Health 47.

Liao Y., D.L. McGee, G. Cao, R.S. Cooper. 2001. Recent changes in the health status of the older U.S. population: Findings from the 1984 and 1994 Supplement on Aging. Journal of the American Geriatrics Society 49(4):443-449.

Manderbacka, K. 1995. Measures of health status. How is health status measured in the 1986 Survey of Living Conditions? (in Finnish, English summary). Helsinki: Statistics Finland, Studies 213.

Manton, K.G., L. Corder, and E. Stallard. 1997. Chronic disability trends in the elderly United States populations: 1982-1994. Proceedings of the National Academy of Sciences of the United States of America 94:2593-2598.

Melzer D, G. Izmirliean, S. G. Leveille, J. M. Guralnik. 2001. Educational differences in the prevalence of mobility disability in old age: The dynamics of incidence, mortality, and recovery. The journals of gerontology. B,Psychological sciences and social sciences 56B(5): $: 294-S 301$.

Mäkelä, M., M. Heliövaara, K. Sievers, P. Knekt, J. Maatela, and A. Aromaa. 1993. Musculoskeletal disorders as determinants of disability in Finns aged 30 years or more. Journal of Clinical Epidemiology 46(6):549-559.

Noro, A., U. Häkkinen, S. Arinen. 2000. Health, functional ability and use of health and social services among ageing Finns in 1996 - Findings of surveys of persons living in long-term care institutions and at home (in Finnish, English summary). Helsinki: STAKES and the Social Insurance Institution, SVT Health Care 2000:2.

Olshansky, S.J. and A.B. Ault. 1986. The fourth stage of the epidemiologic transition: the age of delayed degenerative diseases. Milbank Quarterly 64:355-391.

Ostir, G.V., J.E. Carlson, S.A. Black, L. Rudkin, J.S. Goodwin, K.S. Markides. 1999. Behavioral Medicine 24:147-156.

Pitkälä K., J. Valvanne, S. Kulp, T.E. Strandberg and R.S. Tilvis. 2001. Secular trends in self-reported functioning, need for assistance and attitudes towards life: 10-year differences of three older cohorts. Journal of the American Geriatrics Society 49:596600.

Pohjolainen P., E. Heikkinen, A-L. Lyyra, S. Helin, K. Tyrkkö. 1997. Socio-economic status, health and life-style in two elderly cohorts in Jyväskylä. Scandinavian Journal of Social Medicine, Suppl. 52.

Rahkonen, O. and P. Takala. 1997. Terveydentilan ja toimintakyvyn sosiaaliset erot vanhoilla miehillä ja naisilla (Social differences in health status and functional capacity among older men and women; in Finnish). Gerontologia 11(4):282-291. 
Statistics Finland. 2001. Population projection 2001-2030. Helsinki: Statistics Finland.

Stuck, A.E., J.M. Walthert, T. Nikolaus, C. J. Bula, C. Hohmann and J. C. Beck. 1999. Risk factors for functional status decline in community-living elderly people: a systematic literature review. Social Science \& Medicine 48:445-469.

Sulander T., S. Helakorpi, A. Uutela, P. Puska. 2000. Health Behaviour of the Finnish Elderly, Spring 1999 with trends 1993-1999. Helsinki: Publications of the National Public Health Institute B7/2000.

Trovato, F. and N.M. Lalu. 1996. Narrowing sex differentials in life expectancy in the industrialized world: early 1970's to early 1990's. Social Biology 43(1-2):20-37.

Valkonen, T. 1999. The widening differentials in adult mortality by socio-economic status and their causes. In Chamie, J. and R.L. Cliquet, editors. Health and Mortality. Issues of Global Concern. Proceedings of the symposium on Health and Mortality, Brussels, 1922 November 1997. Leuven: Population Division, Department of Economic and Social Affairs, United Nations Secretariat and Population and Family Study Centre, Flemish Scientific Institute.

Valkonen, T., A-P. Sihvonen, E. Lahelma. 1997. Health expectancy by level of education in Finland. Social Science and Medicine 44(6):801-808.

Verbrugge, L.M. 1984. Longer life but worsening health? Trends in health and mortality of middle-aged and older persons. Milbank Memorial Fund Quarterly 62(3):475-519.

Waidmann T.A. and K. Liu. 2000. Disability trends among elderly persons and implications for the future. Journal of Gerontology: Social Sciences 55B(5):S298-S307.

Winblad I., M. Jääskeläinen, S-L. Kivelä, P. Hiltunen, P. Laippala. 2001. Prevalence of disability in three birth cohort at old age over time spans of 10 and 20 years. Journal of Clinical Epidemiology 54:1019-1024. 